\title{
Quality of life in patients with scabies in Erbil, Iraq
}

\author{
Received: 06/07/2020
}

Accepted: 01/ 11/ 2020

\begin{tabular}{rrr}
\hline Khalis Bilal $^{1 *}$ & Samir M. Othman $^{1}$ & Yassin Ahmad Asaad $^{1}$ \\
\hline Abstract &
\end{tabular}

Background and objective: Scabies, known as the seven-year itch, is a contagious skin infestation by the mite Sarcoptes scabiei that causes a pruritic skin eruption. Scabies is endemic in most of the communities of the developing world. This study aimed to assess the quality of life of scabies patients, taking into consideration the demographic profile and clinical presentation of patients in Erbil.

Methods: In this cross-sectional study, 107 scabies patients attending a private dermatology clinic were recruited. Dermatology Quality of Life Index questionnaire was used for data collection.

Results: More than half (51.4\%) of the patients were less than 30 years of age, including $58.9 \%$ males, $70.1 \%$ of them were married, and $67.3 \%$ were living in the urban area. More than $84 \%$ of the study sample's quality of life was very large and extremely large affected. The overall mean of the quality of life scores was $14.95 \pm 4.5$ with no significant association between the overall quality of life scores to disease severity and certain sociodemographic characteristics of the patients. The mean scores of the two domains of embarrassment and shopping were significantly associated with the male gender $(P=0.003$ and 0.021 , respectively). However, $40.2 \%, 35.5 \%$, and $29 \%$ of the patients reported that the disease affected very much on their shopping, clothing, and working activities, respectively.

Conclusion: The disease had caused a significant effect on patients' lives, with no significant association between the severity of the disease and overall quality of life scores. The disease in its mild, moderate, and severe forms adversely affected patient lives. The commonest quality of life scores were those in the range of 11-20.

Keywords: Quality of life; Scabies; Erbil; Iraq.

\section{Introduction}

Scabies, known as the seven-year itch, is a contagious skin infestation by the mite Sarcoptes scabiei that causes a pruritic skin eruption. It is endemic in most rural communities of the developing world, with a prevalence rate of up to $10 \%$ in the general population. ${ }^{1,2}$ The predominant symptom of scabies infestation is pruritus, which can be debilitating. Disruption of the skin's protective barrier function promotes secondary bacterial infections, which can lead to more potentially life-threatening complications and, in severe cases, can lead to renal and cardiac diseases., ${ }^{3,4}$

The disease is transmitted through direct and prolonged contact with infected skin or rarely contaminated personal objects. It has a significant impact in terms of cost of treatment, absence at work or school, and psychological consequences. ${ }^{2}$ it affects both genders of all socioeconomic statuses and races. ${ }^{1}$ Some studies had reported higher rates in urban areas with an increased incidence during winter months. ${ }^{5}$ Also, there is an increased risk of outbreaks in facilities with crowded living conditions in which large numbers of people live in close contact with each other, and the disease is one of the skin infections with health impact. ${ }^{6,7}$ Although scabies had previously been considered as

${ }^{1}$ Department of Community Medicine, College of Medicine, Hawler Medical University, Erbil, I raq.

* Correspondence: khalis.bilal@hmu.edu.krd 
a neglected disease, it was only added to the World Health Organization list of neglected tropical diseases in October 2013. ${ }^{8-10}$ As scabies could not be eliminated, morbidity control is the only choice to reduce the burden of the disease. The illness is not only expressed by the degree of clinical pathology but also affects the emotional aspects of the patients. ${ }^{1}$ It was found that itching can cause moderate to severe sleep disturbance in the majority of patients and affects the daily life activities of the patients in many ways. ${ }^{11}$ Over the past few years, there has been an increasing concern in assessing the quality of life of patients with skin diseases as well as in the improvement of assessment methods. This was validated in a study in the USA, where most of the patients suffered from itching and discomfort in addition to sleep disturbance. $^{12}$

The concept of quality of life is often used in healthcare research and has become an important outcome variable. Quality of life tends to highlight factors that are important in affecting the overall patient's wellbeing; accordingly, quality of life is rated as an important predictor of treatment success and is predicted as of prognostic importance throughout the course of patient's care. $^{13}$

Scabies infestation has a negative impact on the quality of life for infected individuals resulting in considerable stigmatization and isolation in addition to the limitation of social and sporting activities as the scabies usually affects exposed areas of the skin. ${ }^{14}$ A study in China revealed that scabies patients often feel restrictions in their personal relationships. ${ }^{15}$ Also, studies in other parts of the world showed that scabies significantly affects the quality of life. This study aimed to assess the quality of life of scabies patients, taking into consideration the demographic profile and clinical presentation of the patients in Erbil governorate.

\section{Methods}

Study design: A cross-sectional study was conducted from $1^{\text {st }}$ September to $31^{\text {st }}$ December 2018 to assess quality of life in patients with scabies attending a private clinic of dermatology in Erbil.

Data collection: The data was collected from patients with clinical criteria of scabies through Dermatology Life Quality Index (DLQI) questionnaire. DLQI questionnaire was developed in 1994 by Cardiff University, department of dermatology, was the first dermatology-specific quality of life instrument. It is a simple 10-question validated questionnaire that has been used in over 40 different skin conditions in over 80 countries and is available in over 90 languages. In the current study, English, Saudi Arabic, and Kurdish language version were used. It was handed to the patients according to their wills and language abilities. DLQI questionnaire is designed for use in adults, i.e., patients aged 16 years and over. The questionnaire was handed to the patient to fill it, after explanation of the purpose of the study, in those with low education, supported by the researcher. The questionnaire is composed of 10 questions related to symptoms and feelings, daily activities, leisure, work and school, personal relationships, and treatment, with four or five options for each question to be chosen by the patients. The scoring of each question is as follows; very much scored 3 , a lot 2 , a little 1 , not at all 0 , not relevant 0 , and unanswered question 0 score. The DLQI is calculated by summing up the score of each question resulting in a maximum of 30 and a minimum of 0 . The higher the score, the more quality of life is impaired. DLQI Scores classified as follows; from 0-1 mean no effect at all on patient's life, 2-5 mean small effect on patient's life, 6-10 mean moderate effect on patient's life, 11-20 mean very large effect on patient's life, and 21-30 mean extremely large effect on patient's life. ${ }^{16}$

The diagnosis was based on the clinical decision of the dermatology specialists, 
any suspicious cases were excluded from the study, and the cases were categorized into four groups; one body area of skin involvement means mild, two body areas mean moderate, three body areas mean severe, and four and more body areas mean very severe. ${ }^{17}$

\section{Statistical analysis:}

The obtained data were analyzed using the statistical package for the social sciences (SPSS) software version 22. Two approaches were used, a descriptive one to produce frequencies and percentages and an analytic approach, including Chi-square and Fishers' Exact tests to assess categorical variables. Kruskal Wallis Test and Mann-Whitney Test were used to compare between tested mean ranks. A $P$ value of $\leq 0.05$ was considered statistically significant.

\section{Ethical consideration:}

The study protocol was approved by the research ethics committee of the College of Medicine, Hawler Medical University. Verbal consent was obtained from each participant after clarifying the aim of the study.

\section{Results}

The results showed that out of 107 patients enrolled in the study, the mean age \pm SD was $31.64 \pm 12.8$ years, their age ranged from $16-70$ years, more than half $(51.4 \%)$ of them were less than 30 years of age, including $58.9 \%$ males, with a male to female ratio of $1.4: 1$. Around $70.1 \%$ of them were married, and $67.3 \%$ were living in urban areas. Other details of the sociodemographic characteristics of the patients are shown in Table 1.

Table 1 Sociodemographic characteristics of the study sample

\begin{tabular}{|c|c|c|}
\hline Variables & No. & $\%$ \\
\hline \multicolumn{3}{|l|}{ Age groups in years } \\
\hline$<30$ & 55 & 51.4 \\
\hline $30-49$ & 41 & 38.3 \\
\hline$\geq 50$ & 11 & 10.3 \\
\hline \multicolumn{3}{|l|}{ Gender } \\
\hline Male & 63 & 58.9 \\
\hline Female & 44 & 41.1 \\
\hline \multicolumn{3}{|l|}{ Marital status } \\
\hline Single & 32 & 29.9 \\
\hline Married & 75 & 70.1 \\
\hline \multicolumn{3}{|l|}{ Residency } \\
\hline Urban & 72 & 67.3 \\
\hline Rural & 35 & 32.7 \\
\hline \multicolumn{3}{|l|}{ Educational level } \\
\hline Illiterate/ Primary & 41 & 38.3 \\
\hline Intermediate & 15 & 14.0 \\
\hline Secondary school & 22 & 20.6 \\
\hline Graduates * & 29 & 27.1 \\
\hline \multicolumn{3}{|l|}{ Occupation } \\
\hline Unskilled manual & 6 & 5.6 \\
\hline Semi-skilled manual & 56 & 52.3 \\
\hline Skilled manual & 37 & 34.6 \\
\hline Others ** & 8 & 7.5 \\
\hline Total & 107 & 100 \\
\hline
\end{tabular}


Regarding the severity of the disease in relation to the overall quality of life scores, among $33(30.8 \%)$ cases with mild disease form, $57.6 \%$ of them stated that disease had a large effect on their life. Nearly half $(46.7 \%)$ of the patients reported the moderate effect of the disease, and among them, $80 \%$ reported a very large effect of the disease on their life. The same was true for those with the severe form of the disease, with no statistically significant association between the severity of the disease and overall quality of life scores $(P=0.169)$, Table 2 . The overall mean \pm S.D. of the quality of life scores was $14.95 \pm 4.5$ ranged from $4-27$.

Duration of the disease varied among the patients; more than half $(56.1 \%)$ of them presented with the duration of one month or less, and the others had a longer disease duration (Figure 1).

Table 2 Association between disease severity and overall scores of quality of life

\begin{tabular}{|c|c|c|c|c|c|c|c|c|c|}
\hline \multirow{3}{*}{ Variables } & \multicolumn{6}{|c|}{ Quality of life scores } & & & \multirow{3}{*}{$P$ value ** } \\
\hline & \multicolumn{2}{|c|}{$\begin{array}{c}\text { Moderate } \\
\text { effect } \\
\text { Scores (6-10) }\end{array}$} & \multicolumn{2}{|c|}{$\begin{array}{c}\text { Very large } \\
\text { effect } \\
\text { Scores (11-20) }\end{array}$} & \multicolumn{2}{|c|}{$\begin{array}{c}\text { Extremely } \\
\text { large effect } \\
\text { Scores }(21-30)\end{array}$} & \multicolumn{2}{|c|}{ Total * } & \\
\hline & No. & $\%$ & No. & $\%$ & No. & $\%$ & No. & $\%$ & \\
\hline \multicolumn{10}{|c|}{ Disease severity } \\
\hline Mild & 9 & 27.3 & 19 & 57.6 & 5 & 15.2 & 33 & 30.8 & \multirow{4}{*}{0.169} \\
\hline Moderate & 6 & 12.0 & 40 & 80.0 & 4 & 8.0 & 50 & 46.7 & \\
\hline Severe & 2 & 8.3 & 19 & 79.2 & 3 & 12.5 & 24 & 22.4 & \\
\hline Total & 17 & 15.9 & 78 & 72.9 & 12 & 11.2 & 107 & 100.0 & \\
\hline
\end{tabular}

*: Column percentage

**: Fishers' Exact Test

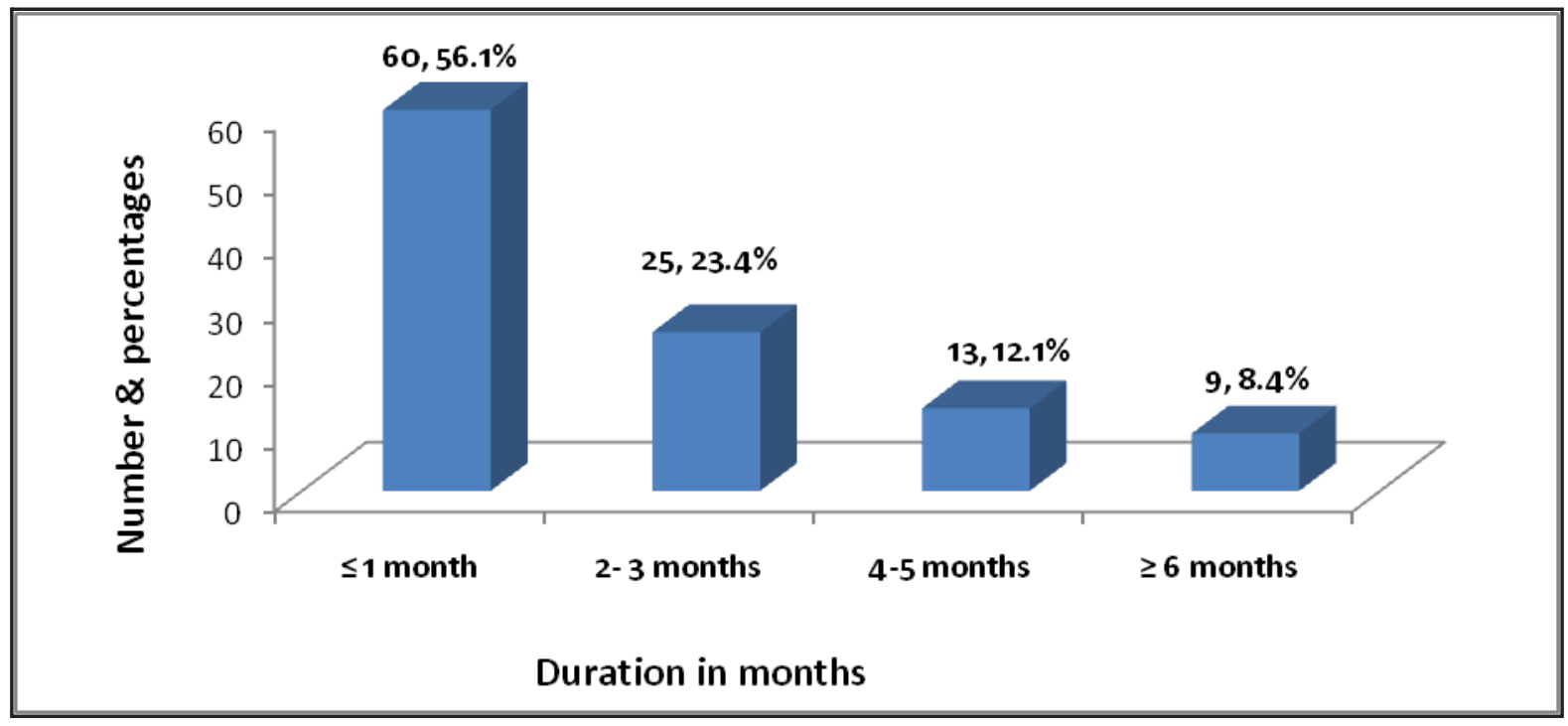

Figure 1 Study sample by disease duration in months 
The majority $(85.0 \%)$ of the patients were receiving treatment at the time of their first consultation to the dermatology clinic, compared to only $15.0 \%$ who were not on treatment (Figure 2).

The disease had produced a very large effect on patients life across all the variables (patients age groups, educational level, and occupation) with no significant statistical association between quality of life scores to the above mentioned sociodemographic characteristics $(P=$ $0.219,0.231$, and 0.47 , respectively), as shown in Table 3.

Table 3 Association between sociodemographic characteristics and overall scores of quality of life

\begin{tabular}{lcccc}
\hline Variables & $\begin{array}{c}\text { Quality of life scores } \\
\text { (Scores 6-10) } \\
\text { No. \& (\%) }\end{array}$ & $\begin{array}{c}\text { Very large effect } \\
\text { (Scores 11-20) } \\
\text { No. \& (\%) }\end{array}$ & $\begin{array}{c}\text { Extremely large effect } \\
\text { (Scores 21-30) } \\
\text { No. \& (\%) }\end{array}$ & P value * \\
\hline Age groups & $13(23.6)$ & $37(67.3)$ & $5(9.10)$ & \\
$<30$ years & $3(7.10)$ & $33(78.6)$ & $6(14.3)$ & 0.219 \\
30- 50 years & $1(10.0)$ & $8(80.0)$ & $1(10.0)$ & \\
$>$ 51years & & & & \\
Education level & $8(19.5)$ & $31(75.6)$ & $2(4.9)$ & \\
Illiterate/ Primary & $4(26.7)$ & $10(66.7)$ & $1(6.7)$ & \\
Intermediate & $3(13.6)$ & $14(63.6)$ & $5(22.7)$ & \\
Secondary school & $2(6.90)$ & $23(79.3)$ & $4(13.8)$ & \\
Graduates ** & & & & \\
Occupation & $2(33.3)$ & $4(66.7)$ & 0.47 \\
Unskilled manual & $8(14.3)$ & $43(76.8)$ & $5(8.0)$ & \\
Semi-skilled manual & $7(18.9)$ & $25(67.6)$ & $5(13.5)$ & \\
Skilled manual & $0(0.00)$ & $6(75.0)$ & $2(25.0)$ & \\
Others *** & $\mathbf{1 7 ( 1 5 . 9 )}$ & $\mathbf{7 8 ( 7 2 . 9 )}$ & $\mathbf{1 2}(\mathbf{1 1 . 2})$ & \\
Total & & &
\end{tabular}

*: Fischer's exact test

**: Including technical institute and college graduates

***: Including associate professionals, skilled professionals, and senior managers

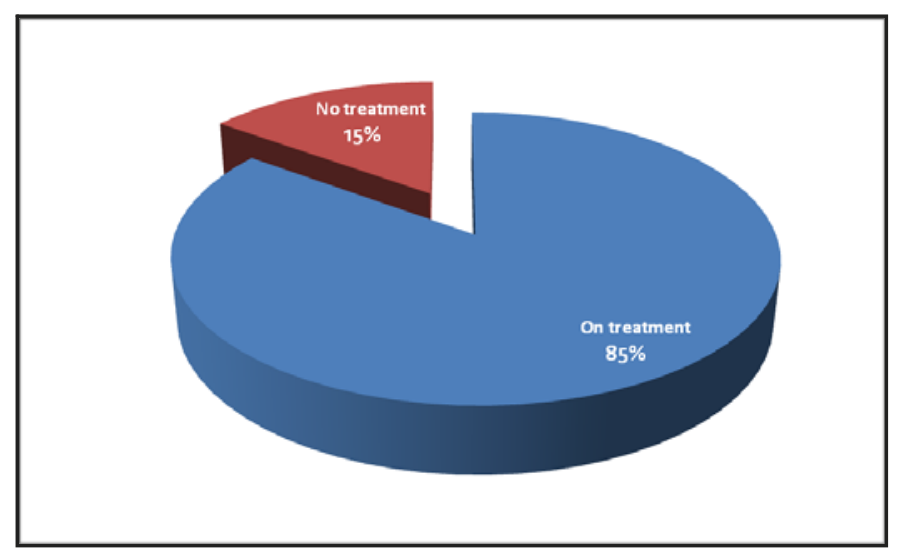

Figure 2 Treatment pattern among the patients on presentation 
Comparing mean scores of quality of life of different domains to age groups of the patients, there was no significant statistical difference through all the domains, except that related to types of clothes worn by the patients $(P=0.041)$, as those aged $>50$ years had reported higher mean scores (74.7) compared to other age groups (Table 4).

Table 4 Mean scores of quality of life in different domains by age groups

\begin{tabular}{|c|c|c|c|c|c|c|c|}
\hline \multirow{3}{*}{ Domains } & \multicolumn{6}{|c|}{ Age groups in years } & \multirow{3}{*}{$P$ value * } \\
\hline & \multicolumn{2}{|c|}{$\begin{array}{c}<30 \text { years } \\
(\mathrm{N}=55)\end{array}$} & \multicolumn{2}{|c|}{$\begin{array}{c}30-50 \text { years } \\
(\mathrm{N}=42)\end{array}$} & \multicolumn{2}{|c|}{$\begin{array}{c}>50 \text { years } \\
(\mathrm{N}=10)\end{array}$} & \\
\hline & Mean \pm SD & $\begin{array}{l}\text { Mean } \\
\text { rank }\end{array}$ & Mean \pm SD & $\begin{array}{l}\text { Mean } \\
\text { rank }\end{array}$ & Mean \pm SD & $\begin{array}{l}\text { Mean } \\
\text { rank }\end{array}$ & \\
\hline Itching & $1.56 \pm 0.53$ & 58.04 & $1.47 \pm 0.63$ & 52.10 & $1.20 \pm 0.42$ & 39.8 & 0.125 \\
\hline Embarrassing & $1.83 \pm 1.01$ & 50.81 & $2.19 \pm 0.67$ & 60.18 & $1.60 \pm 1.17$ & 45.6 & 0.182 \\
\hline Shopping & $1.83 \pm 1.19$ & 54.21 & $1.78 \pm 1.27$ & 53.82 & $1.90 \pm 1.10$ & 53.6 & 0.997 \\
\hline Clothing & $1.56 \pm 1.21$ & 49.17 & $1.80 \pm 1.17$ & 55.39 & $2.6 \pm 0.51$ & 74.7 & 0.041 \\
\hline Social & $1.63 \pm 1.09$ & 52.35 & $1.73 \pm 1.08$ & 55.12 & $1.90 \pm 0.87$ & 58.35 & 0.800 \\
\hline Sport & $0.81 \pm 1.56$ & 53.76 & $1.02 \pm 1.37$ & 56.57 & $0.40 \pm 0.96$ & 44.5 & 0.433 \\
\hline Working & $1.21 \pm 1.14$ & 48.86 & $1.64 \pm 1.18$ & 59.24 & $1.70 \pm 1.41$ & 60.25 & 0.187 \\
\hline $\begin{array}{l}\text { Problem with } \\
\text { partners }\end{array}$ & $1.36 \pm 1.16$ & 49.83 & $1.71 \pm 1.11$ & 59.04 & $1.60 \pm 1.07$ & 55.8 & 0.320 \\
\hline $\begin{array}{l}\text { Sexual } \\
\text { difficulties }\end{array}$ & $0.74 \pm 1.05$ & 49.83 & $1.16 \pm 1.22$ & 60.51 & $0.70 \pm 0.94$ & 49.6 & 0.153 \\
\hline $\begin{array}{l}\text { Treatment } \\
\text { problems }\end{array}$ & $1.38 \pm 1.19$ & 50.75 & $1.73 \pm 1.14$ & 60.06 & $1.20 \pm 1.22$ & 46.4 & 0.222 \\
\hline
\end{tabular}

*: Kruskal Wallis Test 
Comparing mean scores of quality of life in different domains to the gender of the patients, it was significantly different in the two domains of embarrassment and shopping $(P=0.006$ and 0.012, respectively). Males significantly had higher mean scores than females ( 60.43 vs. 44.8 and 59.98 vs.45.44, respectively), while it was not significant in relation to other domains (Table 5).

Regarding patients' response to different questions of quality of life, more than half $(54.2 \%)$ of the patients complained of little itching, while $45.8 \%, 40.2 \%$, and $28.0 \%$ of them stated that the disease caused a lot of embarrassment, social and partner interaction problems, respectively. However, $40.2 \%, 35.5 \%$, and $29 \%$ of the patients reported that the disease affected very much on their shopping, clothing, and working activities, respectively. On the other hand, more than half of the patients had no problem with playing sports or sexual difficulties in relation to the disease (63.6\% and $56.1 \%$, respectively), Table 6 .

Table 5 Mean scores of quality of life in different domains by gender

\begin{tabular}{lccccc}
\hline \multicolumn{5}{c}{ Domains } & \multicolumn{5}{c}{ Mender $(\mathbf{N}=\mathbf{6 3})$} & \multicolumn{2}{c}{ Female $(\mathbf{N}=\mathbf{4 4})$} & \\
& Mean \pm SD & Mean rank & Mean \pm SD & Mean rank & P value * \\
\hline Itching & $1.5 \pm 0.59$ & 54.37 & $1.47 \pm 0.55$ & 53.47 & 0.865 \\
Embarrassing & $2.17 \pm 0.79$ & 60.43 & $1.63 \pm 1.0$ & 44.80 & 0.006 \\
Shopping & $2.04 \pm 1.18$ & 59.98 & $1.5 \pm 1.19$ & 45.44 & 0.012 \\
Clothing & $1.74 \pm 1.17$ & 53.51 & $1.77 \pm 1.20$ & 54.70 & 0.837 \\
Social & $1.73 \pm 1.03$ & 54.53 & $1.65 \pm 1.12$ & 53.24 & 0.824 \\
Sport & $0.93 \pm 1.26$ & 55.23 & $0.75 \pm 1.18$ & 52.24 & 0.567 \\
Working & $1.54 \pm 1.22$ & 56.59 & $1.27 \pm 1.14$ & 50.30 & 0.284 \\
Problem with partners & $1.60 \pm 1.17$ & 56.19 & $1.40 \pm 1.08$ & 50.86 & 0.366 \\
Sexual difficulties & $0.98 \pm 1.13$ & 56.28 & $0.79 \pm 1.13$ & 50.74 & 0.313 \\
Treatment problems & $1.55 \pm 1.23$ & 55.30 & $1.43 \pm 1.13$ & 52.14 & 0.590 \\
\hline
\end{tabular}

*: Mann-Whitney test

Table 6 Patients responses to questions on the quality of life domains

\begin{tabular}{lcccccccc}
\hline Quality of life domains & \multicolumn{2}{c}{ Not at alll } & \multicolumn{2}{c}{ A little } & \multicolumn{2}{c}{ A lot } & \multicolumn{2}{c}{ Very much } \\
& not relevant & \multicolumn{2}{c}{} & & & & \\
& No. & (\%) & No. & (\%) & No. & (\%) & No. & (\%) \\
\hline Itching & 0 & $(0.00)$ & 58 & $(54.2)$ & 45 & $(42.1)$ & 04 & $(3.70)$ \\
Embarrassed & 11 & $(10.3)$ & 15 & $(14.0)$ & 49 & $(45.8)$ & 32 & $(29.9)$ \\
Effect on shopping & 27 & $(25.2)$ & 8 & $(7.50)$ & 29 & $(27.1)$ & 43 & $(40.2)$ \\
Clothing & 26 & $(24.3)$ & 12 & $(11.2)$ & 31 & $(29.0)$ & 38 & $(35.5)$ \\
Social & 22 & $(20.6)$ & 15 & $(14.0)$ & 43 & $(40.2)$ & 27 & $(25.2)$ \\
Sport & 68 & $(63.6)$ & 7 & $(6.50)$ & 11 & $(10.3)$ & 21 & $(19.6)$ \\
Working & 32 & $(19.9)$ & 28 & $(26.2)$ & 16 & $(15.0)$ & 31 & $(29.0)$ \\
Problem with partners & 28 & $(26.2)$ & 22 & $(20.6)$ & 30 & $(28.0)$ & 27 & $(25.2)$ \\
Sexual difficulties & 60 & $(56.1)$ & 10 & $(9.30)$ & 24 & $(22.4)$ & 13 & $(12.1)$ \\
Treatment problems & 32 & $(29.9)$ & 18 & $(16.8)$ & 28 & $(26.2)$ & 29 & $(27.1)$ \\
\hline
\end{tabular}




\section{Discussion}

Scabies is considered one of the neglected tropical diseases. The disease burden estimated in disability-adjusted life-years is more in tropical regions among children, adolescents, and elderly people. In 2018, the World Health Organization recognized the need for a global strategy for scabies control, such a strategy would align with the United Nations Sustainable Development Goals, including Target 3.3 to end the epidemic of neglected tropical disease by 2030 . $^{8,18}$

In this study, out of 107 scabies patients, the mean age \pm SD of the patients was $31.64 \pm 12.8$ years, their ages ranged from 16-70 years, more than half of them were less than 30 years of age, including more males than females, with a male to female ratio of 1.4:1. A study in Lao included 140 patients, their ages ranged from 4 months to 92 years with a 0.7 male/female ratio and the most affected age groups were young patients. ${ }^{19}$ The possible cause behind this similarity could be that the young age groups are more active and more exposed to the external environment accordingly. They have a higher chance of getting the disease than other age groups.

In the current study, more than two-thirds of the patients were married and living in the urban area. Studies in Fiji and Egypt revealed a higher prevalence of the disease in rural areas. ${ }^{20,21}$ Married patients could have more chances to be infected with the disease because of frequent skin to skin contact. Also, the disease was more prevalent in the urban area in our community; this could be because most of the patients were from the city center, and the dermatology clinic was better access to them. Infection of one person in the family is usually followed by the infection of the other households. Thus, just as the individual becomes diseased, the entire population (family) can become sick.

The study showed that more than $84 \%$ of the study sample were very largely and extremely large affected, which reflects the poor quality of life of scabies patients.
The main suffering of the patient is severe pruritus, mostly at night, interrupting sleeping, and the poor sleep is affecting the productivity of the person at day time.

This study showed that nearly more than half of those patients with mild disease form reported a large effect on their lives. The majority of those who reported a moderate effect of the disease suffered from very large effect of the disease on their lives. The same was true for those with a severe form of the disease, with no statistically significant association between the severity of the disease and overall quality of life scores $(P=0.169)$. The overall mean $\pm S D$ of the quality of life scores were $14.95 \pm 4.5$ ranged from 4-27. This was in contrast to the results of a study in India, where only half of the adult patients reported little effect on their quality of life. ${ }^{1}$ A study in Pakistan indicated a very large effect of scabies on patients quality of life with a mean \pm SD of $16.76 \pm 2.54 .13$ Other studies in Brazil showed that scabies patients had experienced a very large effect on the quality of life. ${ }^{22,23}$ It is clear that most of the skin disorders had some effect on the patients' quality of life taking into consideration the social, economic and educational factors. Also, allergic sensitivity to the mite or its products appears to play an important role in determining the development of lesions other than burrows and in producing pruritus.

Duration of the disease varied among the patients. More than half $(56.1 \%)$ of them presented with a duration of one month or less. Others had a longer disease duration. Similar results were found in a study conducted in Duhok, Iraq, where more than three fourth of the patients sought medical consultation in a period of less than four weeks. ${ }^{24}$ Itching is considered an embarrassing symptom affecting scabies patients. Accordingly, they seek medical consultation with the early onset of the disease. The delay in seeking medical consultation in other patients could be due to the time of itching, which is mostly at 
night and the daytime itching is trivial, making them postpone the consultation.

In this study, the majority $(85.0 \%)$ of the patients were receiving treatment at the time of their first consultation to the dermatology clinic. A study in Nigeria showed that only $66.7 \%$ sought medical treatment. ${ }^{25}$ This could be because patients in our community had better awareness and more access to health care facilities.

The disease had produced a considerable effect on the patients' lives across all the variables (patients age groups, educational level, and occupation) with no significant statistical association between quality of life scores to the above mentioned sociodemographic characteristics $(P=0.219,0.231$, and 0.47 , respectively). Almost similar results were reported in studies in Cameron and other parts of Iraq, where the severity of the disease is not significantly related to some sociodemographic characteristics of the disease, including age and educational levels. $^{2,26}$ This may be explained on the basis that the sensation of itch is a biological issue rather than being an age, education, or occupation variation. While a study in Poland revealed that an improvement in socioeconomic conditions could contribute to the decrease in scabies infections. ${ }^{27}$ This could be related to better awareness of highly educated people to their health status, the ways of prevention, and seeking early treatment in Poland society.

In comparing mean scores of quality of life of different domains to age groups of the patients, there was no significant statistical difference through all the domains, except that related to types of clothes worn by the patients $(P=0.034)$, as those aged $\geq 50$ years had reported higher mean scores (74.7) compared to other age groups. A study in Pakistan among patients with different skin diseases revealed no significant association of quality of life scores to the age of the patients. ${ }^{28}$

In comparing mean scores of quality of life in different domains to the gender of the patients, the comparisons were significantly different in the two domains of embarrassment and shopping $(P=0.003$ and 0.021 , respectively). Males significantly had reported higher mean scores compared to females, while it was not significant in relation to other domains. A study in Brazil revealed that women and girls perceived more restrictions than men and boys. ${ }^{22}$ However, a study in Cameron showed that men were significantly more affected than females. ${ }^{2}$ The itch reflects various components of the immune response against mites and eggs. However, the severity of the disease has nothing to do with the sociodemographic characteristics of the patients, except the males who were more exposed to the external environment compared to females, accordingly; have more chance to be infected with the disease.

In this study, more than half of the scabies patients complained of little itching, while others stated that the disease caused a lot of embarrassment, social and partner interaction problems. Others had reported that the disease affected very much their shopping, clothing, and working activities, andmore than half of the patients had no problem with playing sports or sexual difficulties in relation to the disease severity. A study in China revealed that scabies patients suffered a lot of embarrassment, sexual difficulties, and much effect on their work or study environment. Also, there was no strong relationship between quality of life and disease-related characteristics, where the disease moderately affected the quality of life of the patients. ${ }^{15}$ This may be because severe pruritus is an immune response to the parasite and its products regardless of the involved skin surface, which is mostly due to scratching of the patient. This indicates that the severity of the itch is not measured by the involved surface area but by the immune response of the patient to antigen antibody reaction.

This study had certain limitations since the data were collected from a single private 
institution, and the results could not be generalized to the whole population. Nevertheless, this article provides baseline data on quality of life of scabies patients, which could enhance future research to address different quality of life domains.

\section{Conclusion}

In conclusion, young age, male gender, and marriage were the main risk factors for the disease. In its mild, moderate, and severe forms, the disease adversely affected patient lives. The commonest quality of life scores were those in the range of 11-20. The association between disease severity and overall quality of life scores was not statistically significant.

\section{Funding}

None.

\section{Competing interests}

None declared.

\section{References}

1. Nair PA, Vora RV, Jivani, S NB, Gandhi HS. A study of clinical profile and quality of life in patients with scabies at a rural tertiary care centre. J Clan Diagn Res. 2016; 10 (10):WC01-5. https://doi.org/10.7860/JCDR/2016/20938.8703.

2. Kouotou EA, Nansseu JR, Kouawa MK, Bissek AZ. Prevalence and drivers of human scabies among children and adolescents living and studying in Cameroonian boarding schools. Parasit Vectors. 2016; 9:2-6. https://doi.org/10.1186/s13071-016-1690-3.

3. Karimkhani $\mathrm{CH}$, Colombara DV, Drucker AM, Norton SA, Hay R, Engelman D, et al. Theglobal burden of scabies: a cross-sectional analysis from the Global Burden of Disease Study 2015. Lancet Infect Dis. 2017; 17:1247-54. https://doi.org/10.1016/S1473-3099(17)30483-8.

4. Bhat SA, Mounsey KE, Liu X, Walton SF. Host immune responses to the itch mite, Sarcoptesscabiei, in humans. Parasit Vectors. 2017; 10(1):385. https://doi.org/10.1186/ s13071-017-2320-4.

5. Alsamarai AM. Frequency of scabies in Iraq: Survey in a dermatology clinic. J Infect Dev Ctries. 2009; 3(10):783-9. https://doi.org/10.3855/ jidc. 144 .

6. Dressler C, Rosumeck S, Sunderkötter C, Werner RN, Nast A. The treatment of scabies: A systematic review of randomized controlled trials. Dtsch Arztebl Int. 2016; 113:757-62. https://doi.org/10.3238/arztebl.2016.0757.
7. Alsamarai AM, Alobaidi AH. Scabies in displaced families: Health care problem that need urgent action. Our Dermatol Online. 2017; 8(3):250-4.

8. Aiempanakit K. Crusted scabies in a patient with methamphetamine abuse. JAAD Case Rep. 2018; 4(5):480-1. https://doi.org/10.1016/ j.jdcr.2018.01.008.

9. Romani L, Steer AC, Whitfeld MJ, Kaldor JM. Prevalence of scabies and impetigo worldwide: a systematic review. Lancet Infect Dis. 2015; 15(8):960-7. https://doi.org/10.1016/S1473-3099 (15)00132-2.

10. Sara J, Haji Y, Gebretsadik A. Scabies outbreak investigation and risk factors in East Badewacho District, Southern Ethiopia: Unmatched Case Control Study. Dermatol Res Pract. 2018; 2018:1 -10.https://doi.org/10.1155/2018/7276938.

11. Worth C, Heukelbach J, Fengler G, Walter B. Acute morbidity associated with scabies and other ectoprasitoses rapidly improves after treatment with ivermectin. Pediatr Dermatol. 2011; 29;29 (4):430-6. https://doi.org/10.1111/j.15251470.2011.01680.x.

12. Wang $H$, Yosipovitch $G$. New insights into the pathophysiology and treatment of chronic itch in patients with end-stage renal disease, chronic liver disease and lymphoma. Int J Dermatol. 2010; 49(1):1-11. https://doi.org/10.1111/j.13654632.2009.04249.x.

13. Ghafoor R, Saleem F, Iqbal $Q$, Hassali MA, Hashmi FK, Haider S, et al. Quality of life in patients with skin diseases attending a public healthcare institute of Quetta city. J Pak Pharm Prac Community Med. 2018; 4(1):16-20. https://doi.org/10.5530/jppcm.2018.1.5.

14. Bouvresse S, Chosidow O. Scabies in healthcare settings. Curr Opin Infect Dis. 2010; 23(2):111-8. https://doi.org/10.1097/ QCO.0b013e328336821b.

15. Jin-gang $A$, Sheng-xiang $X$, Sheng-bin $X$, Jun-min W, Song-mei G, Ying-ying D, et al. Quality of life of patients with scabies. J Eur Acad Dermatol Venereol. 2010; 24:1187-91. https://doi.org/10.1111/j.1468-3083.2010.03618.x.

16. Hahn HB, Melfi CA, Chuang TY, Lewis CW, Gonin R, Hanna MP, et al. Use of the Dermatology Life Quality Index (DLQI) in a Midwestern urban clinic. JAAD. 2001; 45(1):44-8. https://doi.org/10.1067/mjd.2001.110880.

17. Hamm H, Beiteke U, Höger P, Seitz C, Thaci D, Sunderkötter C. Treatment of scabies with $5 \%$ permethrin cream: results of a German multicenter study. JDDG. 2006; 4:407-13. https://doi.org/10.1111/j.1610-0387.2006.05941.x.

18. Engelman D, Steer AC. Control strategies for scabies. Trop Med Infect Dis. 2018; 3(98):1-11. https://doi.org/10.3390/tropicalmed3030098.

19. Wootton $\mathrm{Cl}$, Bell S, Philavanh A, Phommachack K, Soukavong M, Kidoikhammouan S. Assessing skin disease and associated health-related quality of life in a rural Lao community. BMC 
Dermatol. 2018; 18(11):2-10. https://doi.org/ 10.1186/s12895-018-0079-8.

20. Romani L, Koroivueta J, Steer AC, Kama M, Kaldor JM, Wand $\mathrm{H}$, et al. Scabies and impetigo prevalence and risk factors in Fiji: A national survey. PLoS Negl Trop Dis. 2015; 9 (3):e0003452. https://doi.org/10.1371/ journal.pntd.0003452.

21. Hegab DS, Karo AM, Kabbash IA, Dabish GM. Scabies among primary schoolchildren in Egypt: sociomedical environmental study in Kafr El-Sheikh administrative area. Clin Cosmet Investig Dermatol. 2015; 8:105-11. https://doi.org/10.2147/CCID.S78287.

22. Worth C, Heukelbach J, Fengler G, Walter $B$, Liesenfeld $O$, Feldmeier H. Impaired quality of life in adults and children with scabies from an impoverished community in Brazil. Int J Dermatol. 2012; 51(3):275-82. https://doi.org/10.1111/j.1365-4632.2011.05017.x.

23. Feldmeier $\mathrm{H}$, Jackson A, Ariza L, Calheiros CM, SoaresVde L, Oliveira FA, et al. The epidemiology of scabies in an impoverished community in rural Brazil: presence and severity of disease are associated with poor living conditions and illiteracy. J Am Acad Dermatol. 2009; 60(3):436-43. https://doi.org/10.1016/j.jaad.2008.11.005.

24. Mero WM, Hassan HK. Incidence of human scabies in Duhok province, Kurdistan region/ Iraq. J University Zakho. 2014; 2(2):285-92.

25. Sambo MN, Idris SH, Umar AA, Olorukooba AA. Prevalence of scabies among school-aged children in Katanga rural community in Kaduna state, Northwestern Nigeria. Ann Nigerian Med. 2012; 6:26-9.

26. Al- Musawi MM, Maluki A, Rasool H. Prevalence of scabies among patients attending the Dermatology outpatient clinic in Najaf governorate, Iraq. J Adv Med Res. 2013; 3(4): 63-70.

27. Korycińska J, Dzika E, Kloch M. Epidemiology of scabies in relation to socioeconomic and selected climatic factors in north-east Poland. Ann Agric Environ Med. 2019; 26(4):512-22. https://doi.org/10.26444/aaem/109319.

28. Shahbaz H, Shabbir S, Maryam J, Amir S, Humayun A. Quality of life in patients with skin diseases on exposed Parts -A study in two teaching hospitals of Lahore. Proceeding SZPGMI. 2017; 31(2):103-10. 